\title{
Clinical significance of fermentation and lactose malabsorption
} By Merete Olesen and Eivind Gudmand-Hфyer

\begin{abstract}
Fermentation, the bacterial process of gaining energy from the breakdown of carbohydrates, takes place in the human large intestine as well as that of the animals. This process is important for the health of the colon. Due to changing dietary habits, the available substrates for fermentation in the human colon are scarce, and this fact may contribute to the increased number of colonic diseases in the Western world. Lactose in lactose-maldigesters increase the amounts of fermentable substrate, and may contribute to the health of the colon in these individuals. The symptoms of lactose maldigestion may be reduced by adaptation.

Keywords: Bacterial flora, colon, fermentation, lactose, prebiotic
\end{abstract}

\begin{abstract}
Introduction
In the 1970 s two different research areas converged. One concentrated on the importance of lactose maldigestion as a cause of the irritable bowel syndrome. When lactose maldigestion initially came under consideration, it was found that some people suffering from the irritable bowel syndrome also had lactose maldigestion. It was proved that removing lactose from these people's diet alleviated at least some of their symptoms (1).

Another focus was on the importance of fermentation and the availability of substrates for fermentation in the human large intestine. A whole new interest in the area of the large intestine as a fermentative organ was started when DP Burkitt published results concerning the frequencies of diseases in the large intestine (2). Diseases like cancer, polyps, diverticular disease, were far less frequent among native Africans living in Africa than among Africans living in the USA.
\end{abstract}

\section{Fermentation in the large intestine}

The principal function for the colon is to rescue water and electrolytes, secreted in the small intestine during digestion, and to provide a route for excretion of waste products. Burkitt's observations brought another aspect of colon function into focus: it is also a huge fermentative organ.

For a long time, veterinarians working in the field have known the importance of microbial fermentation within the rumen to the nutrition of cattle and sheep. Clinicians and alimentary physiologists, working mainly with humans, have tended to regard intestinal bacteria as unfortunate contaminants, of little metabolic significance. It has now been realised that even the human colon is colonised within a few days after birth, and further, that this bacterial colonisation is important to the health of the colon. Patients with surgery of the colon and a blind closure of the upper part of the bowel develop diversion colitis - a condition that is ameliorated when continuity is re-established, and the microbial flora allowed to recolonise the gut lumen. Patients treated with antibiotics that decimate the number of bacteria in the colon may develop diarrhoea or even severe colitis. These diseases are provoked by the lack of fermentation products.

The colon is inhabited by a rich flora of bacteria, most of them

Merete Olesen, MD, Eivind Gudmand-Høyer, MD, Dr.Sci., Dept of Medical Gastroenterology, F, Copenhagen County Hospital, Gentofte, Niels Andersens vej 65, DK-2900 Hellerup, Denmark.

Correspondence: E-mail: gudmand@dadlnet.dk

The article is based on lectures presented at the meeting Lactose intolerance revisited, Febuary 1-2, 2001, Stockholm, Sweden. anaerobic, and most of them saccharolytic, ie they derive their energy primarily from carbohydrates. Carbohydrates in the colon are broken down by the concerted action of many different species of bacteria - a process known as fermentation. During fermentation, apart from energy and substrates for multiplication, the bacteria also produce different substances useful to the host, i.e. the gases $\mathrm{CO}_{2}, \mathrm{CH}_{4}, \mathrm{H}_{2}$ and short chain fatty acids (SCFAs), especially acetate, propionate, butyrate. These substances act in concert to regulate the $\mathrm{pH}$ in the gut. $\mathrm{H}_{2}$ and $\mathrm{CH}_{4}$ are, to the best of our knowledge, inert, and diffuse to the blood or leave the bowel as flatus. The increase in breath hydrogen can be used as a diagnostic test for lactose malabsorption (Figure 1) $\mathrm{CO}_{2}$ and SCFAs facilitate the water and sodium re-absorption in the colon, and the SCFAs are the preferred sources of energy for the colonocytes, the cells lining the colon. Further, the SCFAs are absorbed from the colon, they pass to the liver and they are used in the general energy supply. This is an effect very important to ruminants, while for humans it is only of importance in extreme situations, as in short bowel patients (3). These are the obvious

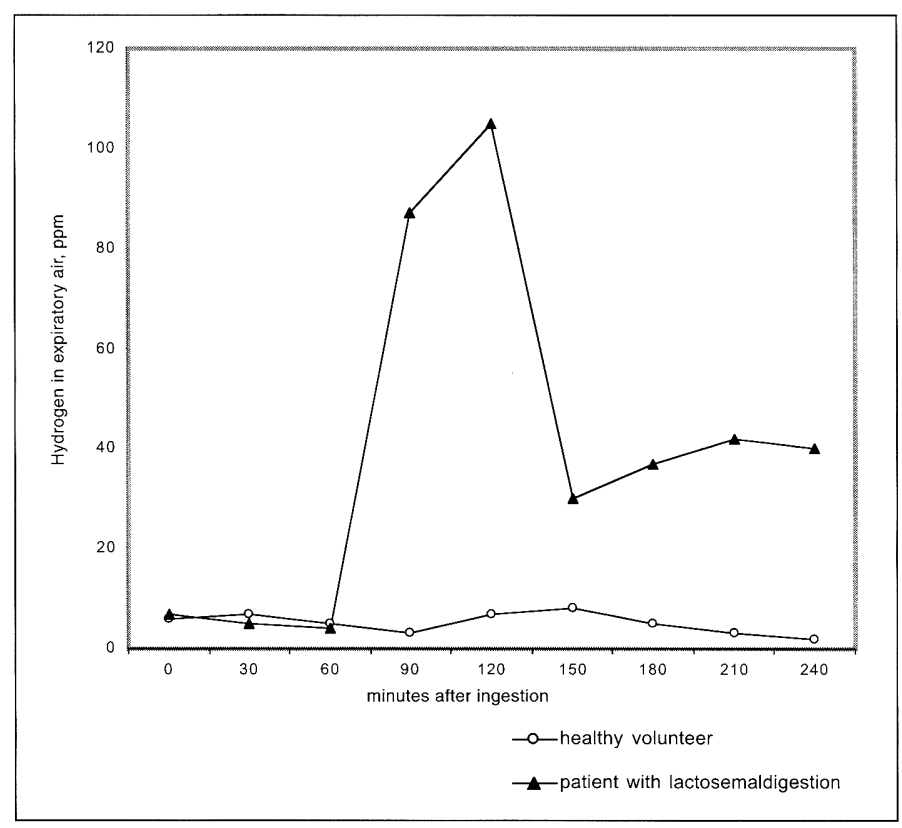

Figure 1. Increase in end expiratory hydrogen in patient suffering from lactose maldigestion after ingestion of $25 \mathrm{~g}$ lactose. The increase mirrors ongoing fermentation by the colonic bacterial flora. The fast fermentation is supposed to be symptom provoking. A healthy volunteer is presented for comparison. 
advantages to the host. It has also been hypothesized that the SCFAs protect against cancer in the colon, that they participate in the regulation of gut hormones and in the gut's microcirculation (overview: 4).

In the human colon a countless number of bacteria reside. It has been calculated that healthy young males with their faeces excrete on an average 20-25 g bacterial mass/day (5). If the bacterial mass is to be renewed at this rate, it can be calculated that the human colonic flora must be supplied with $50-70 \mathrm{~g}$ carbohydrates or carbohydrate degradation products/day, given steady state conditions.

\section{Fermentation substrates}

The general opinion has been that all digestible carbohydrates are absorbed in the small intestine, leaving mainly undigestible dietary fibres as a source of fermentable substrate for the colonic bacterial flora. In the Western world, the intake of dietary fibres amounts to an average of 20-30 g/day. This fact has prompted a search for other sources of fermentable substrate reaching the colon, and resistant starch - starch and starch degradation products undigestible in the human small intestine - has been a candidate. Also, the amount of resistant starch is scarce in the Western diet, maybe 5-7 g/day. Several groups have found that small amounts of otherwise easily digestible starch pass the small intestine to end as a fermentation substrate in the colon $(6,7)$.

One of the problems with a Western diet is that the content of fat is very high, and correspondingly relatively poor in carbohydrates. Thus, on a Western diet, the growth of the colonic bacterial flora may actually be inhibited from lack of fermentable substrates. This point has prompted a search for suitable fermentable substrates that are able to reach the colon, i.e. that are not digested and absorbed in the small intestine.

\section{Prebiotics}

A prebiotic is a non-digestible food ingredient that beneficially affects the host by selectively stimulating the growth, activity, or both of one or a limited number of bacteria in the colon and thus improves the health of the host (8).

Of the natural non-digestible oligosaccharides (and polysaccharides) that fulfil the criteria of colonic food, fructooligosaccharides are the only products currently recognized and used as food ingredients that meet all criteria allowing classification as prebiotics.

Fructooligosaccharides in the healthy human gastro-intestinal tract have much the same effect as lactose in the lactosemaldigesters. Also, it must be anticipated that lactose stimulates the growth of the same bacteria as do fructooligosaccharides.

\section{Lactose maldigestion and disease}

The main concern regarding lactose maldigestion is that it may provoke symptoms of the irritable bowel syndrome, i.e. diarrhoea, flatulence, bloating, and abdominal pain. These are distressing, but not dangerous symptoms. From several studies, we know that these symptoms may be provoked by lactose in lactose maldigesters. It has also been found that adaptation to daily lactose feeding reduces symptoms (9).

In a recent study (10), we have tested the effect of fructooligosaccharides, $20 \mathrm{~g} /$ day in patients suffering from the irritable bowel syndrome. We found it to be well tolerated also by this group of vulnerable patients. There is no reason to believe that lactose in lactose maldigesters behaves differently from fructooligosaccharides in the general population.

\section{Conclusion}

Fermentation is important for the health of the large intestine. On a Western diet, it is difficult to supply the colonic bacterial flora with sufficient amounts of substrate for fermentation. This has led to developing functional foods that fulfil the criteria of prebiotics. Fructooligosaccharides fulfil these criteria in healthy people, and we assume that lactose in lactose maldigesters also can be considered a prebiotic.

Fructooligosaccharides in healthy people, and lactose in lactose maldigesters, may provoke symptoms such as diarrhoea, flatulence, bloating, abdominal pain, but these symptoms are alleviated by adaptation.

\section{REFERENCES}

1. Gudmand-Høyer E, Riis P, Wulff HR: The signicficance of lactose malabsorption in the irritable bowel syndrome. Scand J Gastroenterol 1973:8·273-8.

2. Burkitt DP, Walker AR, Painter NS: Effect of dietary fibre on stools and their transit-time, and its role in causation of disease. Lancet 1972 Dec $30(2)(7792): 1408-12$

3. Olesen M, Gudmand-Høyer E, Jørgensen S: Importance of colonic fermentation in short bowel patients. Small intestinal malabsorption of easily digestible carbohydrate. Dig Dis Sci 1999:44:1914-23.

4. In: Physiological and clinical aspects of short-chain fatty acids. JH Cummings, JL Rombeau, T Sakata (eds). 1995, Cambridge University Press.

5. Stephen AM, Cummings JH: The microbial contribution to human faecal mass. J Med Microbiol 1980:13:45-56.

6. Anderson IH, Levine AS, Levitt MD: Incomplete absorption of carbohydrate in all purpose wheat flour. N Engl J Med 1981;304:891-2.

7. Olesen M, Gudmand-Høyer E: Maldigestion and colonic fermentation of wheat bread in humans and the influence of dietary fat. Am J Clin Nutr 1997;66:62-6.

8. Gibson GR, Roberfroid MB: Dietary modulation of human colonic microbiota: introducing the concept of prebiotics. J Nutr 1995;125:1401-12.

9. Hertzler SR, Savaiano DA: Colonic adaptation to daily lactose feeding in lactose maldigesters reduces lactose intolerance. Am J Clin Nutr 1996;64: 232-6.

10. Olesen M, Gudmand-Høyer E: Efficacy, safety and tolerability of fructooligosaccharides in patients suffering from the irritable bowel syndrome Am J Clin Nutr 2000;72:1570-5. 